\title{
Investigation into Cation-Ordered Magnetic Polar Double Perovskite Oxides
}

Monirul Shaikh, ${ }^{\dagger, \|}$ Aafreen Fathima, ${ }^{\dagger, \|}$ M. J. Swamynadhan, ${ }^{\dagger}$ Hena Das, ${ }^{,+,}, \mathbb{I}$ and Saurabh Ghosh ${ }^{*, \dagger, \S}$

$\dagger$ Department of Physics and Nanotechnology, SRM Institute of Science and Technology, Kattankulathur - 603 203, Tamil Nadu, India

$\ddagger$ Laboratory for Materials and Structures, Tokyo Institute of Technology, 4259 Nagatsuta, Midori-ku, Yokohama, Kana-gawa 226-8503, Japan

\Tokyo Tech World Research Hub Initiative (WRHI), Institute of Innovative Research, Tokyo Institute of Technology, 4259 Nagatsuta, Midori-ku, Yokohama, Kanagawa 226-8503, Japan

$\S S R M$ Research Institute, SRM Institute of Science and Technology, Kattankulathur - 603 203, Tamil Nadu, India

$\|$ Contributed equally to this work

E-mail: das.h.aa@m.titech.ac.jp; saurabhghosh2802@gmail.com

\section{Supporting Information}

\section{Methodology of formation energy calculation}

We have calculated the formation energies for each double perovskites proposed in this work by considering the decomposition reaction of the double perovskites via. most probable reaction pathways. There are many possible reaction sequences that can produce these double perovskites, each of them could lead us to different formations energies, which could 
give erroneous results. Hence, to find the correct formation energy, we need to figure out the minimum energy reaction sequence to produce these double perovskites. We followed a theoretical framework suggested by A. R. Akbarzadeh et. al. Advanced Materials 2007, 19, 3233-3239, (Reference No 75 in the mane text) and made appropriate modifications in order to suit our problem. We have considered all possible stable oxides reported previously, those fall on the energy hull. The reaction energy is calculated by the following expression:

$$
G=\sum_{i} x_{i} F_{i}
$$

Where $G$ is the total reaction energy of the reaction sequences, $i$ includes a set of all possible stable oxides, $F$ is the free energy (at $\mathrm{T}=0 \mathrm{~K}$ ) of the $i$ th compound and $x_{i}$ (unknown) is the variable molar fraction of the $i$ th compound at a given composition. In order to get the minimum energy reaction, we minimized equation (1) with respect to the molar fraction $x_{i}$, with mass conservation constraints such as

$$
f_{s}=\sum_{i} x_{i} n_{i}^{s}=\text { constant }
$$

Where, $n_{i}^{s}$ is the number of ions of species ' $\mathrm{s}$ ' in the $i$ th compound per formula unit and $f_{s}$ is the molar fraction of the individual species 's' ( $\mathrm{s}=\mathrm{Na}, \mathrm{Y}, \mathrm{Mn}, \mathrm{Fe}, \mathrm{Co}, \mathrm{Ni}, \mathrm{W}, \mathrm{Re}, \mathrm{Os}$ and O). To apply the above formalism, we considered a set of all possible stable compounds on the energy hull which contains $\mathrm{Na}, \mathrm{Y}, \mathrm{Mn}, \mathrm{Fe}, \mathrm{Co}, \mathrm{Ni}, \mathrm{W}, \mathrm{Re}, \mathrm{Os}$ and $\mathrm{O}$ as the constituents of the DPs. We have excluded the metal alloys of these $3 d$ and $5 d$ elements, because they need high temperature and pressure to form our considered DPs. We calculated the free energy of these compounds using the same parameters that we used to calculate the energies of DPs. Using these calculated free energies, we minimized the linear equation (1) using linear programming solver and calculated the formation energies with respect to these minimum energy reactions. The respective minimum energy reactions are presented in the form of equations 4-9 and discussed in the main text. The formation energy with respect to the 
respective equation has been shown in Figure 5(c) of the main text. 
Table 1: List of stable oxides considered for computing the formation energies of the double perovskites. Total 69 compounds are considered to find out the minimum energy reaction path.

\begin{tabular}{|c|c|c|c|}
\hline $\begin{array}{l}\text { Stable } \\
\text { oxides }\end{array}$ & $\begin{array}{l}\text { Space } \\
\text { group }\end{array}$ & $\begin{array}{l}\text { Stable } \\
\text { oxides }\end{array}$ & $\begin{array}{l}\text { Space } \\
\text { group }\end{array}$ \\
\hline$\overline{\mathrm{N}} \mathrm{Na}_{2} \mathrm{O}$ & $F m-3 m$ & $\mathrm{ReO}_{3}$ & $P m-3 m$ \\
\hline $\mathrm{Na}_{2} \mathrm{O}_{2}$ & $P-62 m$ & $\mathrm{Re}_{2} \mathrm{O}_{7}$ & $P 2_{1} 2_{1} 2_{1}$ \\
\hline $\mathrm{NaO}_{2}$ & Pnnm & $\mathrm{OsO}_{2}$ & $P_{42} / m n m$ \\
\hline $\mathrm{Y}_{2} \mathrm{O}_{3}$ & $I a-3$ & $\mathrm{OsO}_{4}$ & C2/ $/ c$ \\
\hline $\mathrm{MnO}$ & $F m-3 m$ & $\mathrm{FeWO}_{4}$ & $P \mathscr{2} / c$ \\
\hline $\mathrm{MnO}_{2}$ & $I 4 / m$ & $\mathrm{CoWO}_{4}$ & $P_{2} / c$ \\
\hline $\mathrm{Mn}_{3} \mathrm{O}_{4}$ & I $41 /$ amd & $\mathrm{NiWO}_{4}$ & $P \mathscr{2} / c$ \\
\hline $\mathrm{Mn}_{2} \mathrm{O}_{3}$ & $P b c a$ & $\mathrm{Mn}\left(\mathrm{ReO}_{4}\right)_{2}$ & $P-3$ \\
\hline $\mathrm{Co}\left(\mathrm{ReO}_{4}\right)_{2}$ & $P-3 m 1$ & $\mathrm{Re}_{2} \mathrm{NiO}_{8}$ & $P-3$ \\
\hline $\mathrm{Mn}_{3} \mathrm{WO}_{6}$ & $R-3$ & $\mathrm{Na}_{3} \mathrm{ReO}_{5}$ & $P 3_{1} 2_{1}$ \\
\hline $\mathrm{MnWO}_{4}$ & $P^{2} / c$ & $\mathrm{Na}_{5} \mathrm{ReO}_{6}$ & $C_{2} / m$ \\
\hline $\mathrm{NaYO}_{2}$ & $C^{2} / c$ & $\mathrm{NaReO}_{4}$ & I $41 / a$ \\
\hline $\mathrm{Na}_{2} \mathrm{~W}_{2} \mathrm{O}_{7}$ & $C m c \mathscr{L}_{1}$ & $\mathrm{Na}_{2} \mathrm{OsO}_{4}$ & $P-62 m$ \\
\hline $\mathrm{Na}_{2} \mathrm{~W}_{4} \mathrm{O}_{13}$ & $C 2 / m$ & $\mathrm{Na}_{3} \mathrm{OsO}_{5}$ & $P 3_{1} 2_{1}$ \\
\hline $\mathrm{NaOsO}_{3}$ & Pnma & $\mathrm{Na}_{5} \mathrm{OsO}_{6}$ & $C 2 / m$ \\
\hline $\mathrm{Na}_{2} \mathrm{WO}_{4}$ & $F d-3 m$ & $\mathrm{Y}_{5}\left(\mathrm{ReO}_{6}\right)_{2}$ & $C 2 / m$ \\
\hline $\mathrm{Y}_{3} \mathrm{ReO}_{8}$ & $P \mathscr{2}_{1} / c$ & $\mathrm{YMn}_{2} \mathrm{O}_{5}$ & Pbam \\
\hline $\mathrm{Na}_{4} \mathrm{WO}_{5}$ & $P-1$ & $\mathrm{NaFeO}_{2}$ & $R-3 m$ \\
\hline $\mathrm{Na}_{2} \mathrm{ReO}_{3}$ & $\mathrm{P} 63 / \mathrm{mcm}$ & $\mathrm{YCoO}_{3}$ & Pnma \\
\hline $\mathrm{Y}_{2} \mathrm{WO}_{6}$ & $P \mathscr{Z} / c$ & $\mathrm{Na}_{5} \mathrm{FeO}_{4}$ & $P b c a$ \\
\hline $\mathrm{Y}_{6} \mathrm{WO}_{12}$ & $R-3$ & $\mathrm{Na}\left(\mathrm{CoO}_{2}\right)_{3}$ & $C 2 / m$ \\
\hline $\mathrm{Na}_{4} \mathrm{Mn}_{2} \mathrm{O}_{5}$ & Fddd & $\mathrm{Na}_{8} \mathrm{Fe}_{2} \mathrm{O}_{7}$ & $P \mathscr{Q}_{1} / c$ \\
\hline $\mathrm{NaMn}_{8} \mathrm{O}_{16}$ & $P c$ & $\mathrm{NaCoO}_{2}$ & $R-3 m$ \\
\hline $\mathrm{Na}_{2} \mathrm{Mn}_{3} \mathrm{O}_{7}$ & $P-1$ & $\mathrm{NaMn}_{2} \mathrm{O}_{4}$ & Pnma \\
\hline $\mathrm{Na}_{5} \mathrm{CoO}_{4}$ & $\mathrm{Pbca}$ & $\mathrm{Na}_{2} \mathrm{Mn}_{2} \mathrm{O}_{3}$ & $P 4_{3} 2_{1} 2$ \\
\hline $\mathrm{NaMnO}_{2}$ & $C 2 / m$ & $\mathrm{Na}_{10} \mathrm{Co}_{4} \mathrm{O}_{9}$ & $P-1$ \\
\hline $\mathrm{Na}_{4}\left(\mathrm{CoO}_{2}\right)_{7}$ & $P 6_{3} / m$ & $\mathrm{CoO}$ & $F-43 m$ \\
\hline $\mathrm{Y}_{2} \mathrm{Mn}_{2} \mathrm{O}_{7}$ & $F d 3 m$ & $\mathrm{Na}_{3} \mathrm{CoO}_{24}$ & $P_{42} / m n m$ \\
\hline $\mathrm{YMnO}_{3}$ & $\mathrm{P}_{3} / \mathrm{mmc}$ & $\mathrm{NaNiO}_{2}$ & C2 $/ m$ \\
\hline $\mathrm{Fe}_{3} \mathrm{O}_{4}$ & $F d-3 m$ & $\mathrm{Na}_{5} \mathrm{NiO}_{4}$ & $P b c a$ \\
\hline $\mathrm{CoO}_{2}$ & $I 4 / m$ & $\mathrm{Y}_{2} \mathrm{Fe}_{2} \mathrm{O}_{7}$ & $F d-3 m$ \\
\hline $\mathrm{Co}_{3} \mathrm{O}_{4}$ & $R-3 m$ & $\mathrm{YNiO}_{3}$ & Pnma \\
\hline $\mathrm{NiO}$ & $F m-3 m$ & $\mathrm{Ni}_{3} \mathrm{O}_{4}$ & $\mathrm{Cmmm}$ \\
\hline $\mathrm{FeO}$ & $C \mathscr{2} / m$ & $\mathrm{Fe}_{2} \mathrm{O}_{3}$ & $R-3 c$ \\
\hline $\mathrm{WO}_{3}$ & $\mathrm{P}_{4} / \mathrm{nmm}$ & & \\
\hline
\end{tabular}




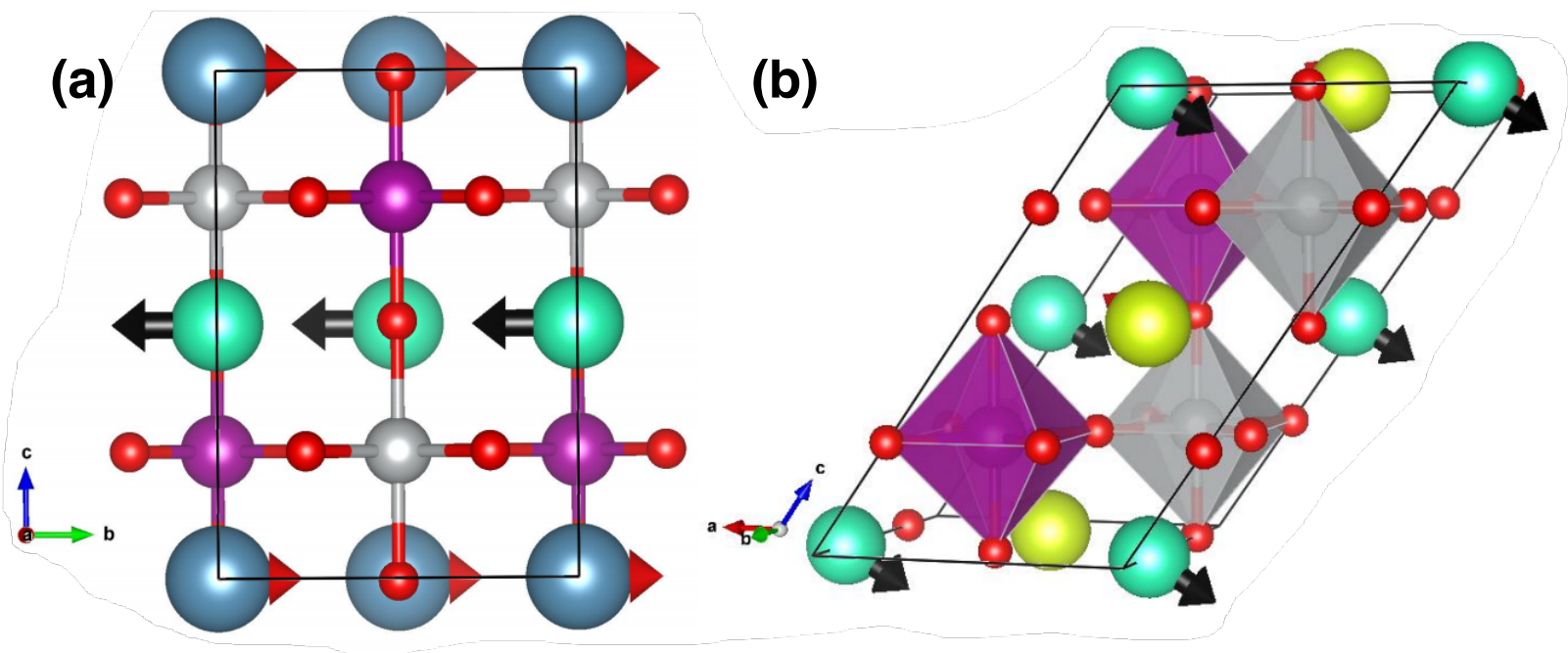

Figure S1: Polar mode in layered and rock salt arrangements. (a) The polar mode in layered ordering $\mathrm{Q}_{p}^{L}$ (irrep. $\Gamma_{5}^{+}$) with respect to $\mathrm{P} 4 / \mathrm{nmm}$ high symmetry and (b) polar mode in rock -salt ordering $\mathrm{Q}_{p}^{R S}$ (irrep. $\Gamma_{4}^{+}$) with respect to $\mathrm{F} \overline{4} 3 \mathrm{~m}$ high symmetry. In case of layered ordering the direction of the polarization is along pseudo cubic [010] direction and in case of rock -salt ordering it is along psedu cubic [111] direction. In case of layered ordering $\mathrm{Q}_{A F E-A}$ becomes polar $\mathrm{Q}_{P}$ due to non-cancelation of the layered in two successive layers.

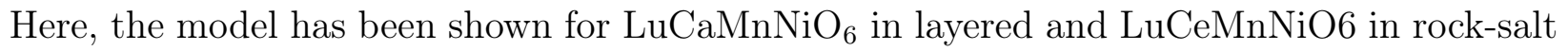
ordering. The blue, yellow, cyan, magenta, silver and red ball represents $\mathrm{Ca}$, Ce, Lu, Mn, $\mathrm{Ni}$ and $\mathrm{O}$ atoms, respectively. 


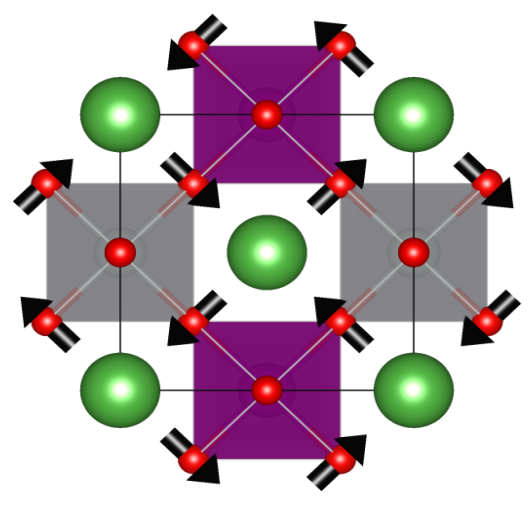

(a) $\operatorname{Rot}\left(a^{0} a^{0} c^{+}\right)$

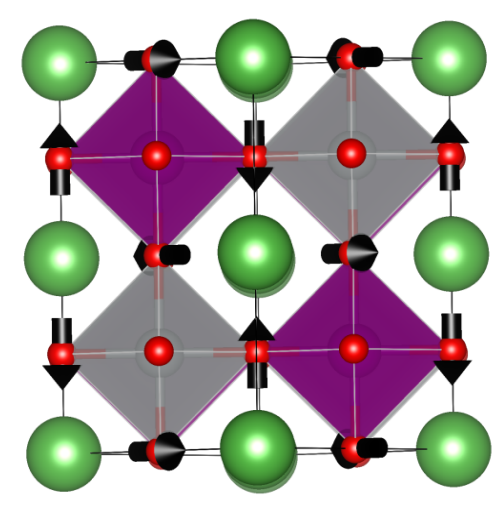

(b) Tilt $\left(\mathrm{a}^{\circ} \mathrm{a}^{-} \mathrm{c}^{0}\right)$

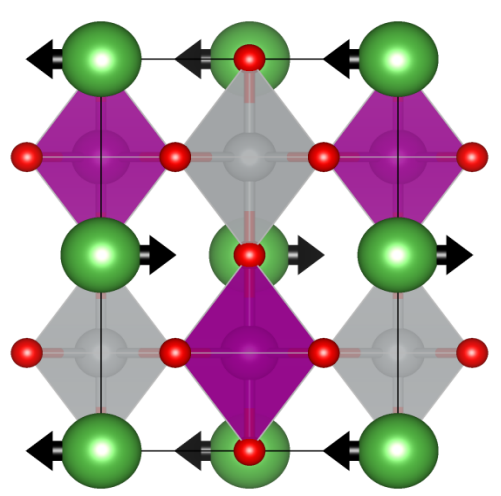

(c) AFE-A

Figure S2: Structural Modes of Trilinear Coupling in orthorhombic $\mathrm{ABO}_{3}$ preovskites. (a) In-phase rotation of $\mathrm{BO}_{6}$ octahedra, $\mathrm{Q}_{\text {Rot }}\left(\mathrm{a}^{0} \mathrm{a}^{0} \mathrm{c}^{+}\right.$, irrep. $\left.M_{3}^{+}\right)$, (b) out of phase rotation of $\mathrm{BO}_{6}$ octahedra, $\mathrm{Q}_{T i l t}\left(\mathrm{a}^{-} \mathrm{a}^{-} \mathrm{c}^{0}\right.$, irrep. $\left.R_{4}^{+}\right)$and (c) $\mathrm{Q}_{A F E-A}$ A-site displacement (irrep. $X_{5}^{+}$) The Glazer pattern is described by the three symmetrize basis modes of the cubic Pm $\overline{3} \mathrm{~m}$. Here, green, magenta, silver and red ball represents La, Mn, Ni and O atom, respectively. 


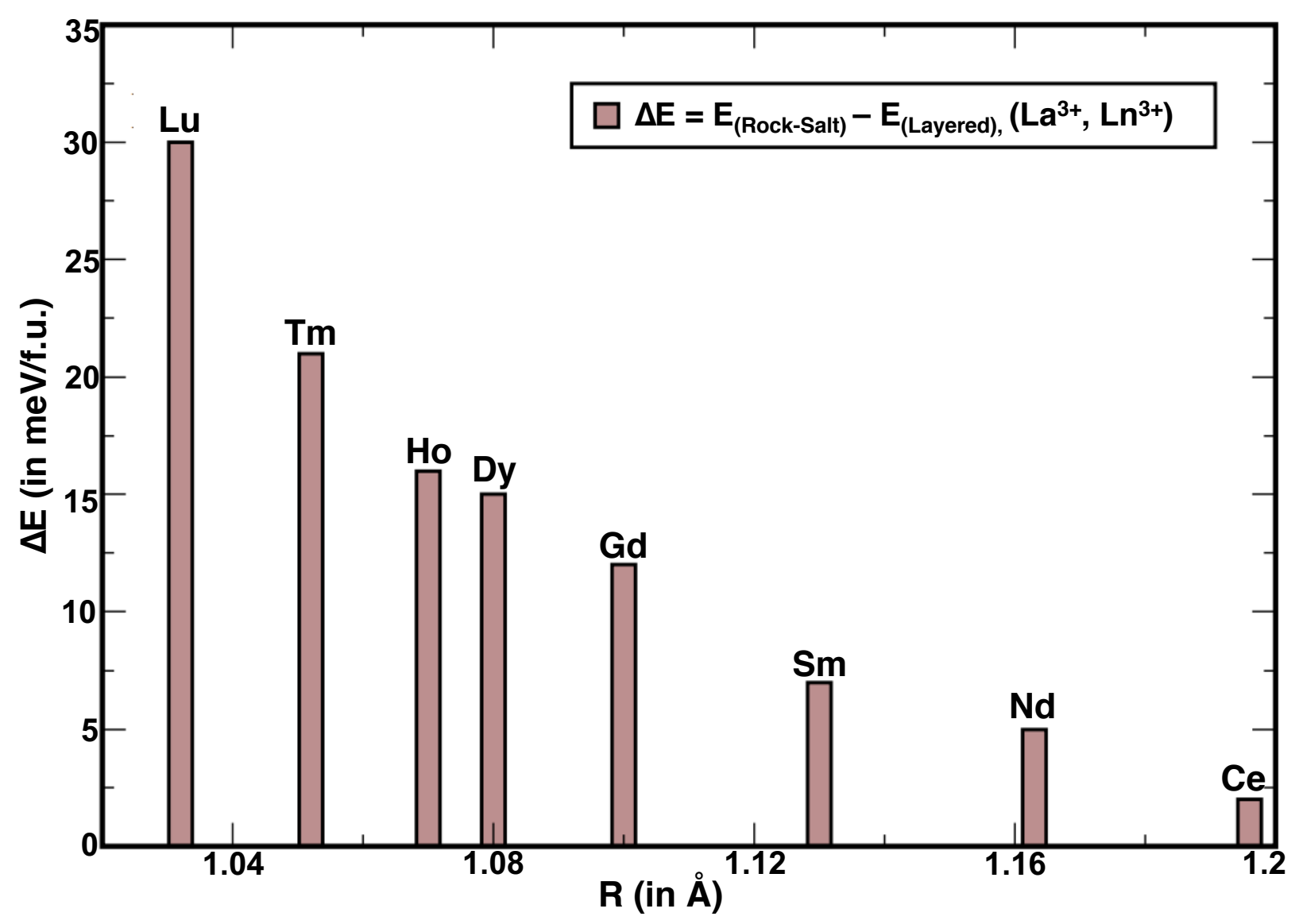

Figure S3: Relative Cation ordering between layered and rock-salt phase for $\mathrm{LnLaMnNiO}_{6}$ systems. Here, $\mathrm{Ln}=\mathrm{Lu}, \mathrm{Tm}, \mathrm{Ho}, \mathrm{Dy}, \mathrm{Gd}, \mathrm{Sm}, \mathrm{Nd}$ and $\mathrm{Ce}$ and all $\mathrm{Ln}$ are in $3+$ oxidation state. No additional carries are doped via. $\mathrm{A}, \mathrm{A}^{\prime}$ combinations. The positive values indicates that he layered ordering is more stable than rock-salt. The relative energy with respect to Columnar phases have not been shown as the magnitudes are much higher. 


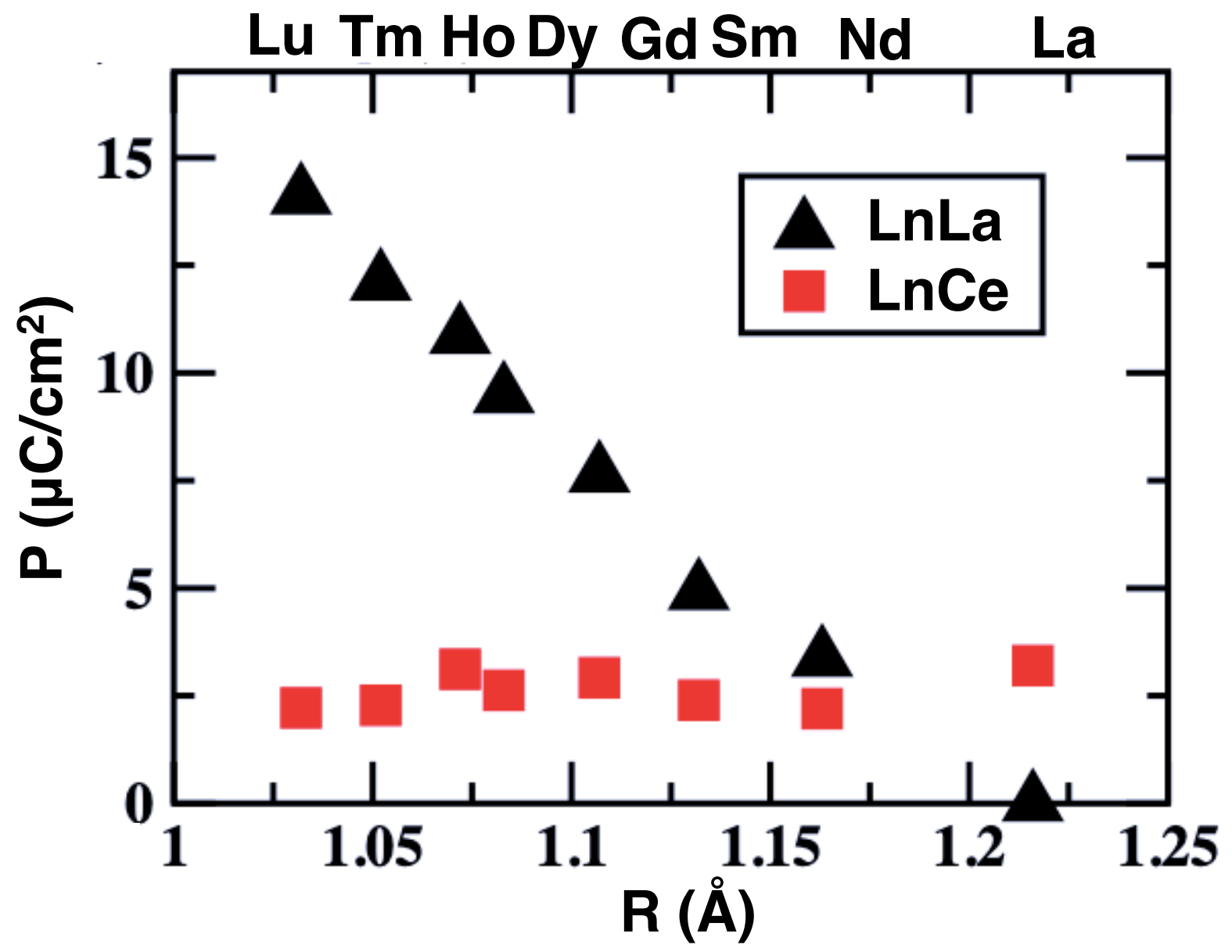

Figure S4: Calculated electric polarization of the layered phase of $\mathrm{LnLaMnNiO}_{6}$ and the rock salt phase of $\mathrm{LnCeMnNiO}_{6}$ systems. Here, $\mathrm{Ln}=\mathrm{Lu}$, Tm, Ho, Dy, Gd, $\mathrm{Sm}, \mathrm{Nd}$ and $\mathrm{La}$ are in $3+$ oxidation state and $\mathrm{Ce}$ is in +4 oxidation state. 

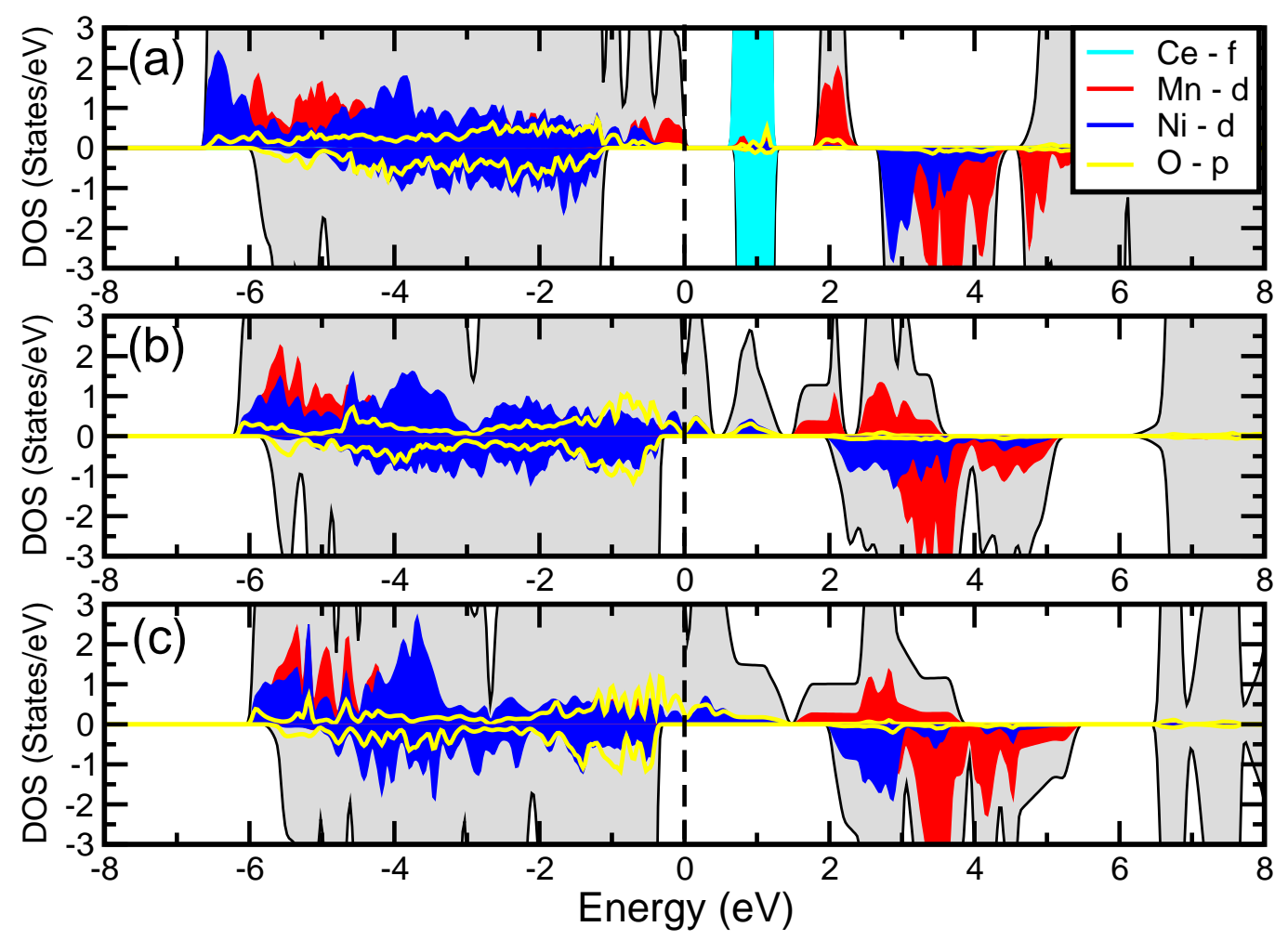

Figure S5: Calculated Density of states (DOS) of (a) $\mathrm{CeYMnNiO}_{6}$, (b) $\mathrm{CaYMnNiO}_{6}$ and (c) $\mathrm{NaYMnNiO}_{6}$. 


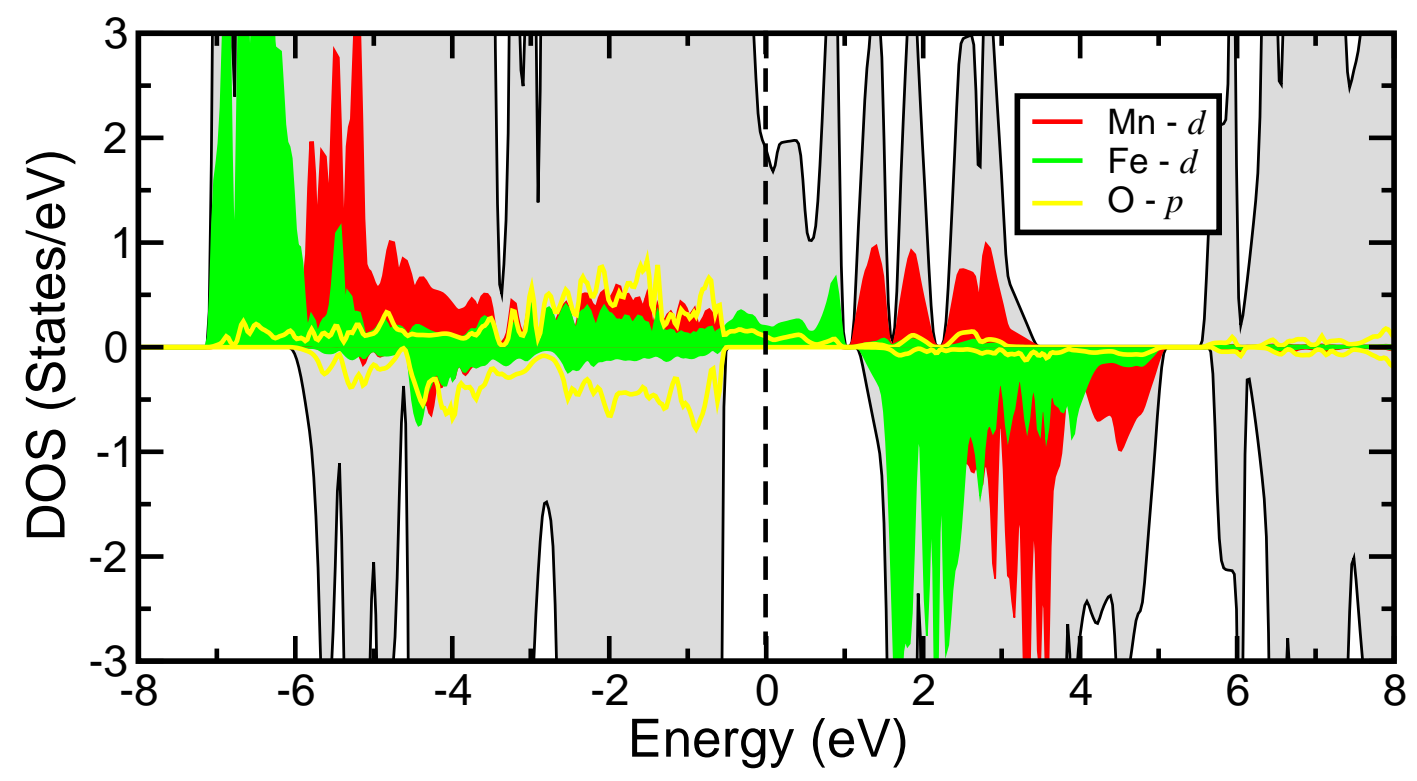

Figure S6: Calculated Density of states (DOS) of $\mathrm{NaYMnFeO}_{6}$ 


\section{Anti-ferro distortive oxygen movement}

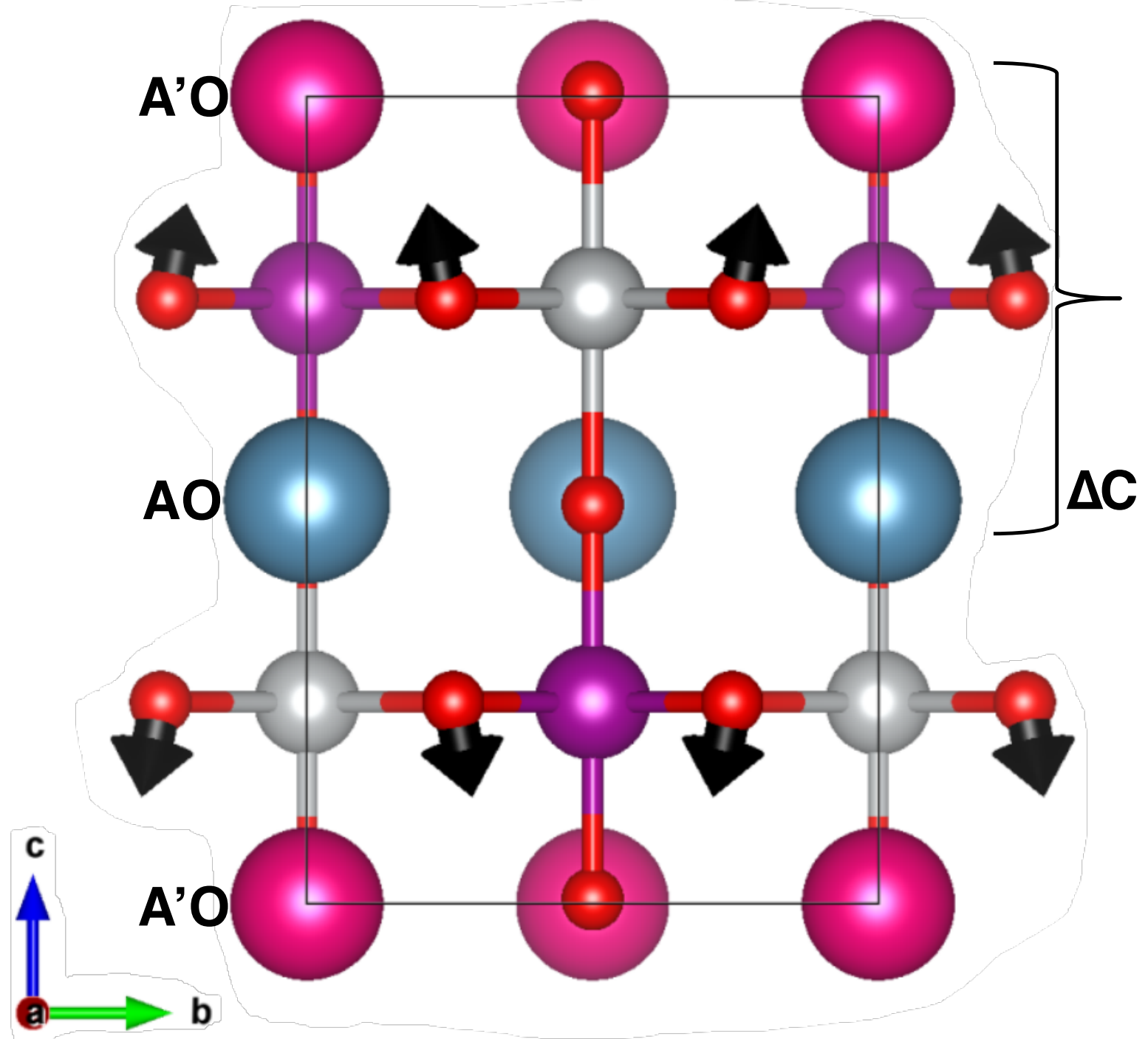

Figure S7: Anti-ferro distortive movement of the oxygen ions originated due to charge difference between $\mathrm{AO}$ and $\mathrm{A}^{\prime} \mathrm{O}$ layer. The in plane oxygen atoms moves towards higher charge layer. 
(a)
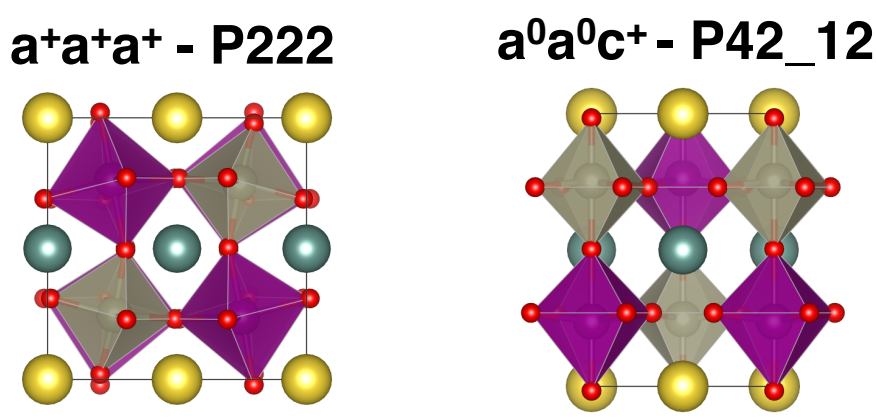

a-a-a- - R3
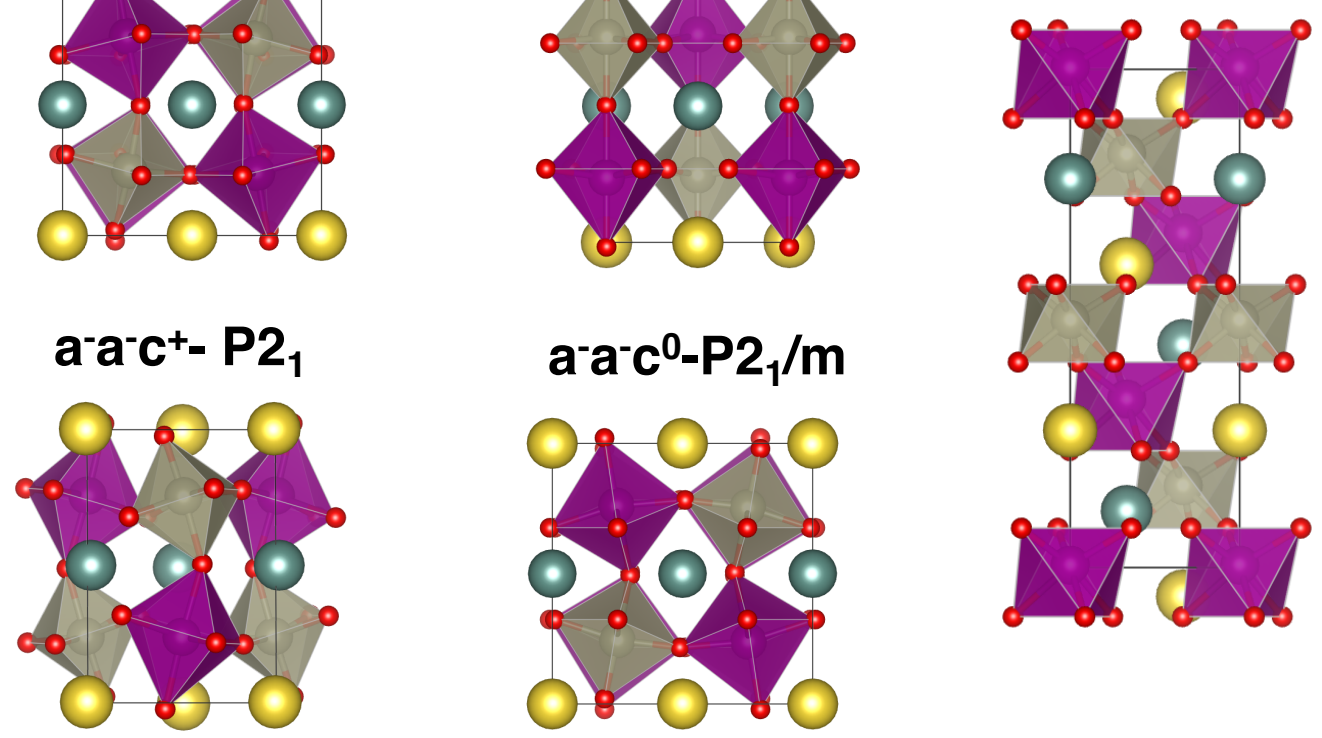

(b)

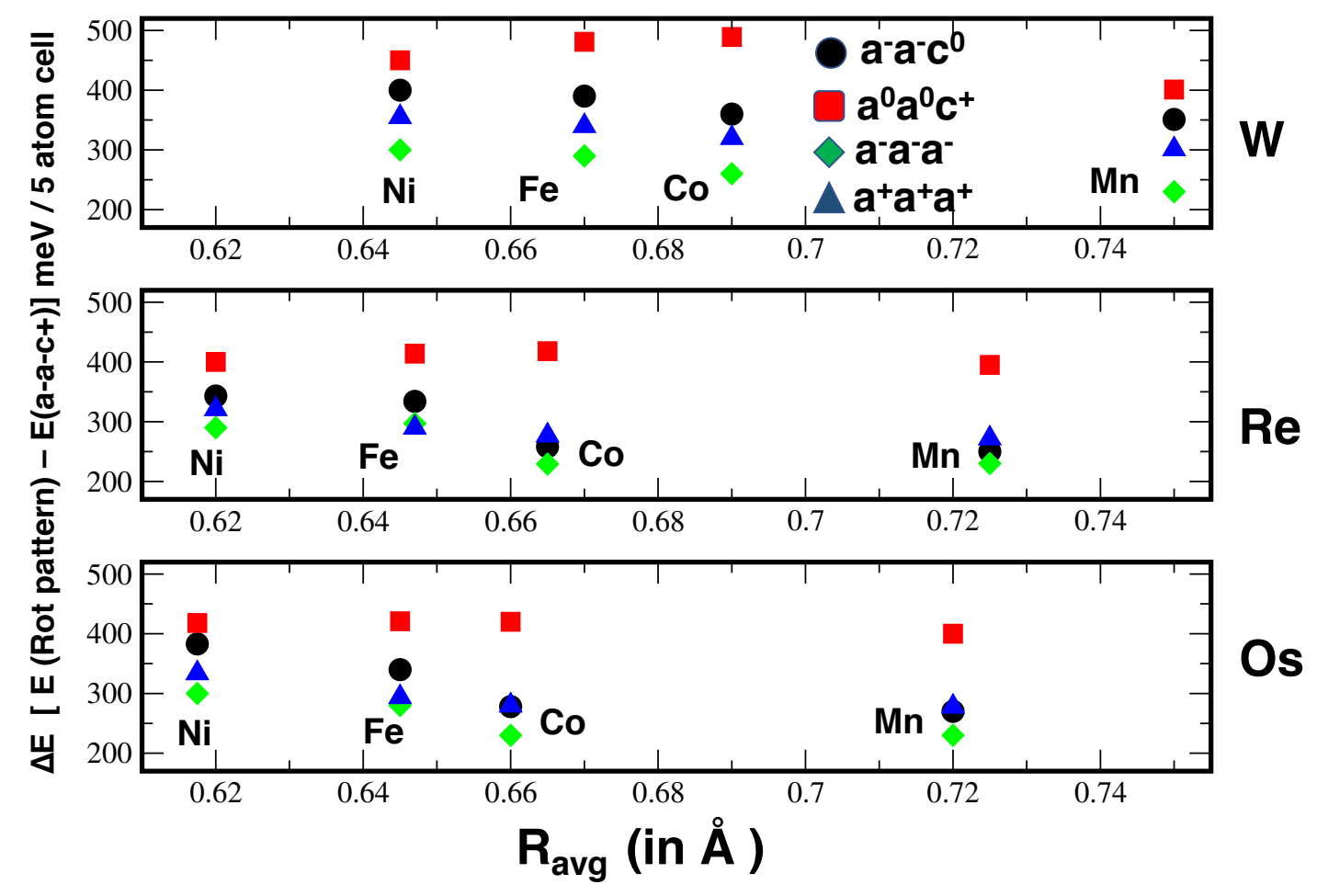

Figure S8: Relative stability of various oxygen rotation pattern with $\mathbf{A} / \mathbf{A}^{\prime}$ cation ordering. (a) Various rotational pattern i.e., $a^{+} a^{+} a^{+}, a^{0} a^{0} c^{+}, a^{-} a^{-} c^{0}, a^{-} a^{-} a^{-}$with $\mathrm{A} / \mathrm{A}^{\prime}$ cation ordering considered for check the stability the rotational patterns with respect to $a^{-} a^{-} c^{+}$. (b) The variation energy difference $\Delta \mathrm{E}=\mathrm{E}$ (Rot pattern) $-\mathrm{E}\left(a^{-} a^{-} c^{+}\right)$with respect to the average $\mathrm{BB}^{\prime}$. The positive energy indicate $\left(a^{-} a^{-} c^{+}\right)$is more stable than other octahedral rotation pattern. 
A-site layered, B-site Rock salt

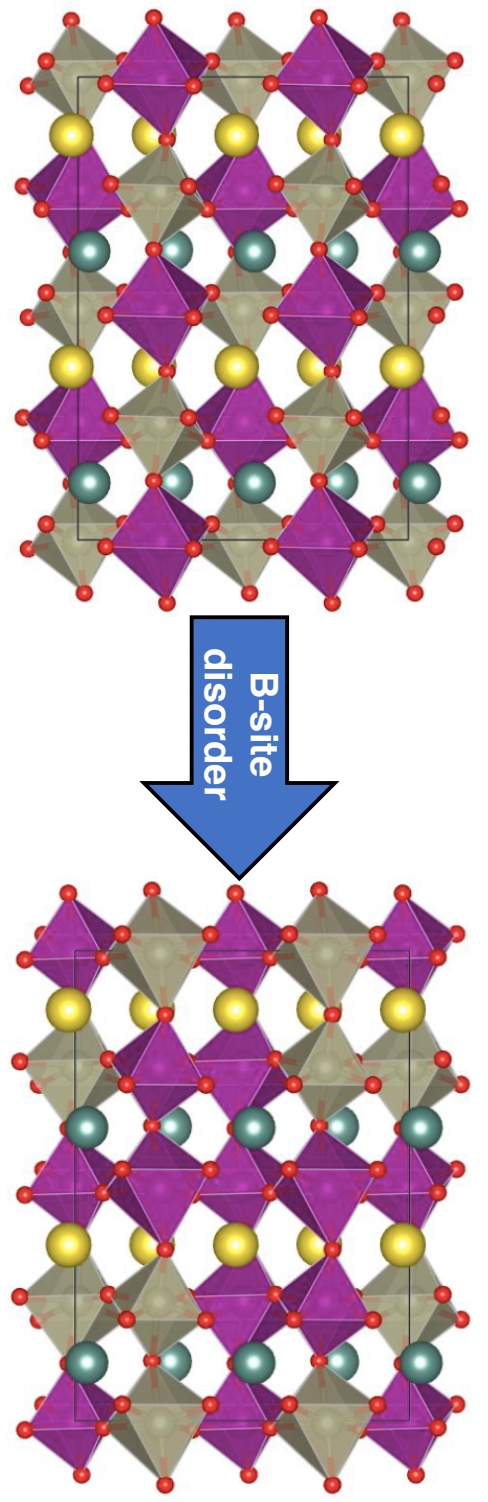

A-site layered, B-site random
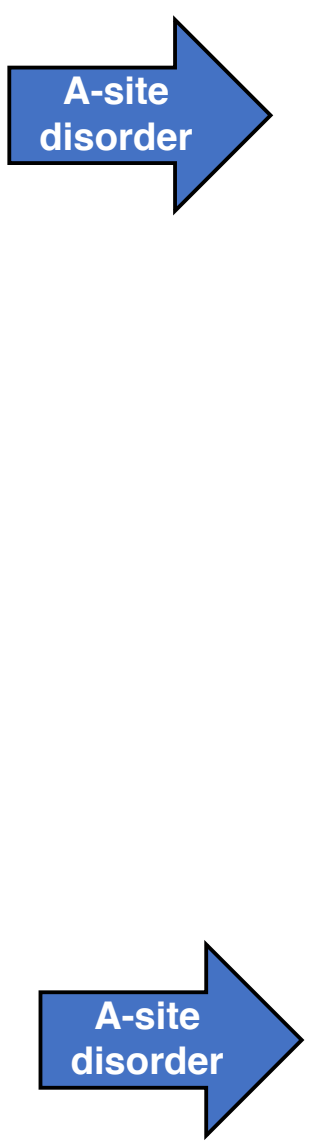

A-site random, B-site Rock salt
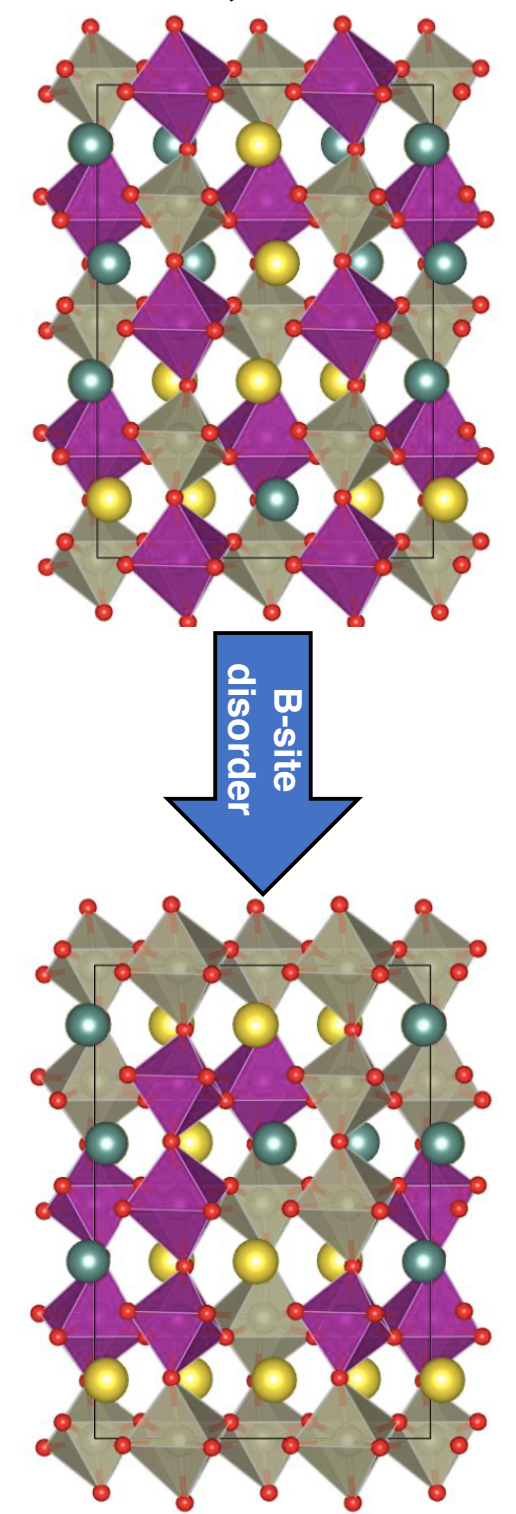

A-site random, B-site random

Figure S9: Generated special quasirandom structures (SQS) of A site disorder, B-site Disorder and both A-site, B site disorder for $\mathrm{NaYMnReO}_{6}$. All the SQS disordered structures lead to the same P1 group symmetry. 


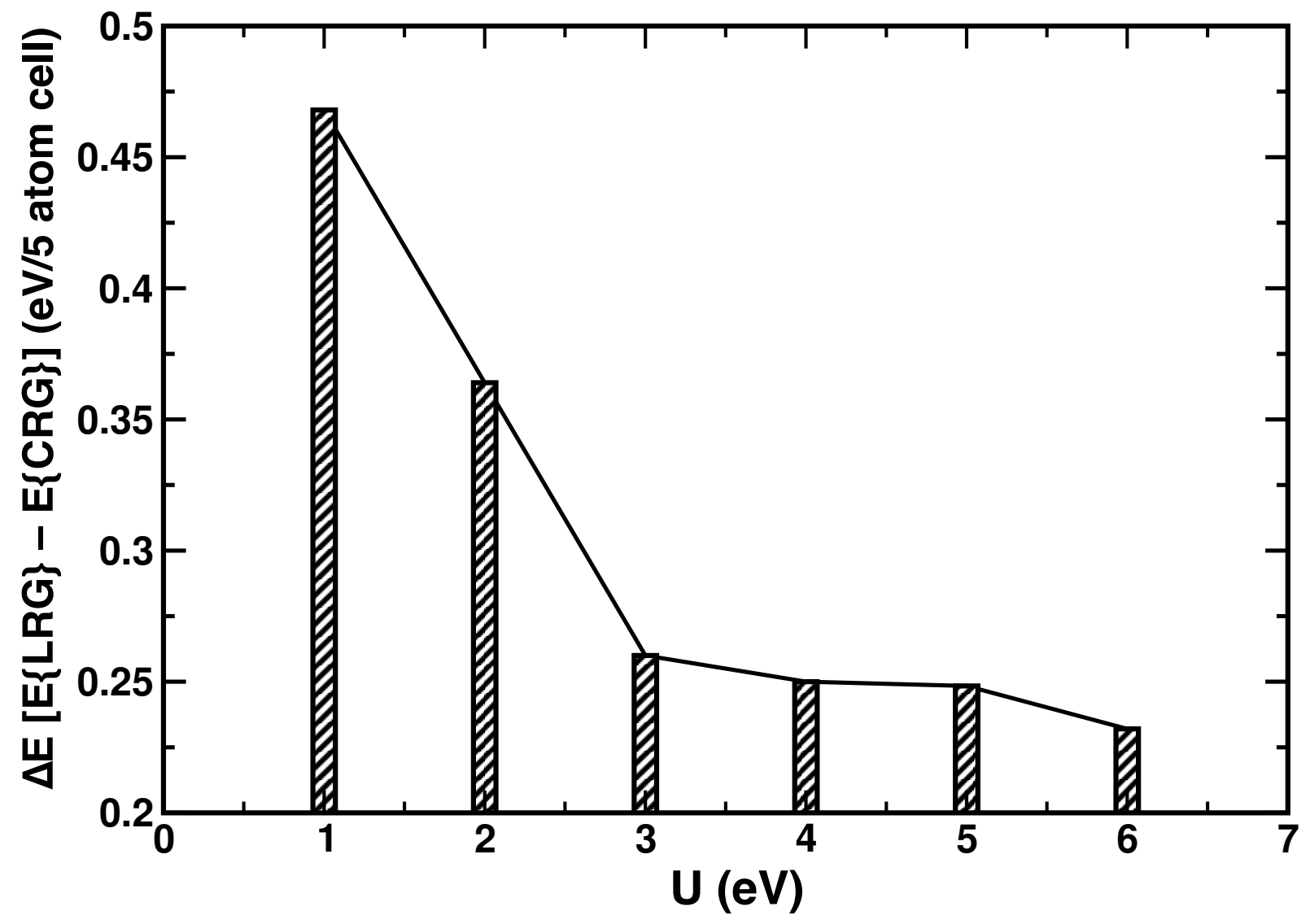

Figure S10: The energy difference between $\mathrm{A}[\mathrm{L}] \mathrm{B}[\mathrm{R}] \mathrm{M}[\mathrm{G}]$ and $\mathrm{A}[\mathrm{C}] \mathrm{B}[\mathrm{R}] \mathrm{M}[\mathrm{G}]$ as function of $\mathrm{U}$ for $\mathrm{NaYCoOsO}_{6}$. 